\title{
The effect of mastication muscular tone on facial size in patients with Down syndrome
}

\author{
Margaretha Suharsini*, Josef Glinka SVD**, and Soekotjo Djokosalamoen*** \\ * Lecture Staff of Department of Pediatric Dentistry, Faculty of Dentistry, University of Indonesia \\ ** Professor Department of Anthropology, Faculty of Social Politics, Airlangga University \\ *** Professor Department of Orthodontics, Faculty of Dentistry, Airlangga University
}

\begin{abstract}
Muscular hypotonia is one of the clinical signs in patients with Down syndrome. As a characteristic of patients with Down syndrome, hypotonia is clearly evident in face expression and oral dysfunction. Dentocraniofacial growth abnormalities in patients with Down syndrome may be influenced by genetic and environmental factors. Stomatognathic system musculature as an environmental factor (factor outside the bone) can affect dentocraniofacial growth by orofacial muscles activities when chewing, swallowing, breathing, and speaking. Oral dysfunctions commonly seen in patients with Down syndrome are open mouth, protruding tongue posture, difficulties when chewing, swallowing, and speaking, drooling, and mouth breathing. The purpose of this study was to observe how the mastication muscular tone affecting the facial size of Down syndrome patient. Twenty five of 14-18 years old children with Down syndrome were diagnosed by clinical characteristic and cytogenetic examination. Mastication muscular tone was described by masseter and temporalis muscle synergy and oral function, whereas the facial size consisted of facial size of lateral, anteroposterior and vertical growth. The result of regression test revealed that the degree of mastication muscular tone has a significant effect on facial size of the anteroposterior growth and facial size of vertical growth, but did not significantly influence the facial size of lateral growth.
\end{abstract}

Key words: mastication muscular tone, facial size, Down syndrome

Correspondence: Margaretha Suharsini, c/o: Bagian Ilmu Kedokteran Gigi Anak, Fakultas Kedokteran Gigi Universitas Indonesia. Jln. Salemba Raya No. 4 Jakarta Pusat, Indonesia.

\section{INTRODUCTION}

The Down syndrome is one of the most common genetic disorders, which clinical neurologic disorders such as muscular hypotonia and mental retardation occur. Muscular hypotonia in children with Down syndrome may affect growth, such as motoric growth and speech impediment. Hypotonia in children with Down syndrome will raise difficulties to move against gravitation, thus resulted in inefficient motoric growth. The manifestations are delay in child's ability to seat, stand, and walk. Children with Down syndrome are able to walk more or less in 2 years of age. ${ }^{1}$

In addition, hypotonia in children with Down syndrome can also manifest in weakness of orofacial musculature, i.e lips, tongue, and cheek. It produces an indistinguishable pronunciation, speech impediment, or stutters, because they cannot hold breathe long enough when saying a whole sentence. In this situation, oral muscular therapy as part of speech therapy program is recommended to increase the muscular tone. ${ }^{2}$

In normal condition, stomatognathic system musculature as an environmental factor (factor outside the bone) may influence dentocraniofacial growth. Stomatognathic system musculature that gives effect to dentocraniofacial is orofacial muscles' activities in chewing, swallowing, breathing, and speaking. These orofacial muscles are referred to mastication, lips and surroundings, tongue, and facial muscles. ${ }^{3,4}$

Hypotonia as a characteristic of patients with Down syndrome is clearly evident in face expressions and oral dysfunctions. Oral dysfunctions commonly seen in these patients are open mouth, protruding tongue, difficulties in chewing, swallowing, and speaking. In addition, drooling and mouth breathing are frequently observed in these patients. $5,6,7$

Macroglossia is a frequent finding in Down syndrome, but it is not clear whether the apparent large tongue in these patients is anatomically enlarge or functionally enlarged as a result of an abnormal forward posture. The narrow maxilla results in lack of space for the tongue may lead the patient to protrude it. This can also gives impression of macroglossia. ${ }^{8}$

Protruded tongue in Down syndrome patients is predicted to cause a dull gonion angle in the mandible, as well as anterior openbite. However, Fischer-Brandies ${ }^{9}$ in his study of children with Down syndrome 0-14 years of age found that gonion angle when they were baby was slightly smaller than normal babies (without Down syndrome). Moreover, he found no difference in gonion angle during growth to 14 years of age, so he concluded that protruded tongue in children with Down syndrome seems to have no effect to gonion angle. This needs a further study, because the likeness of gonion angle between Down syndrome 
patients and normal children can not be assessed only by protruded tongue, yet the forces of mastication muscles need to be considered. It is likely that oral muscular exercises can increase the force of mastication muscles; therefore the craniofacial bone abnormality can be minimized.

Craniofacial can be divided into two sections: cranial section and facial section. Growth of facial section has a closer association with somatic growth and it occurs gradually. Begin with lateral growth, continued with anteroposterior growth, and ultimately vertical growth. ${ }^{10,11}$

Explanation above indicates that muscular hypotonia in patients with Down syndrome can produce disturbance in oral function, and affecting the bone growth in the region of mouth. Therefore, the purpose of this study was to observe the effect of mastication muscular tone on facial size in Down syndrome patients.

\section{MATERIALS AND METHODS}

In this study, male and female between 14-18 years of age with Down syndrome from Sekolah Luar Biasa (Special Schools) in Jakarta was selected. The diagnosis were established clinically by observing the clinical characteristic in children with Down syndrome, and by citogenetic examination, that was, a child with trisomy 21 aberration. Twenty-five children with Down syndrome were chosen, after several approaches and examinations were carried out.

Mastication muscular tone acted as independent variable, described with:12 1) Electromiogram of masseter and temporalis muscle, afterward these muscles were joined as a single variable, that was, masseter-temporalis muscle synergy. 2) Oral function, that was total score of these examinations: a) swallowing; b) chewing, the amount of chew before swallowing $\pm 2 \mathrm{~cm}^{2}$ crackers; c) resting position between upper and lower lip; d) breath habit; e) drooling, involuntary saliva excretion; f) tongue in resting position; g) free way space measurement. Both variables of mastication muscular tone were analyzed, to obtain factor variable of muscular tone factor.

Facial size of lateral, anteroposterior, and vertical growth served as dependent variable: ${ }^{12}$ 1) variables attributed to facial size of lateral growth were: GonionGonion (Go-Go), nose width, maxillary width, mandibular width, face width, inter orbits, Zygion-Zygion (Zy-Zy), Alae nasi-Alae nasi (Al-Al), Endocantion-Endocantion (EnEn); 2) variables attributed to facial size of anteroposterior growth were: maxillary length, mandibular length, SellaNasion-Point A angle (S-N-A), S-N-B angle, ArticulareGonion-Menton angle (Ar-Go-Me); 3) variables attributed to facial size of vertical growth were: ANS-Menton (ANS-Me), Nasion-ANS (N-ANS), Nasion-Gnathion (N-Gn), Nasion-Subnasale (N-Sn), Ramus Mandibulae, Sella-Gonion (S-Go).

After factor analysis of all three variable groups was carried out, each factor variable of facial size of lateral growth, facial size of anteroposterior growth, and facial size of vertical growth was obtained. Regression test was carried out to observe the effect of degree of mastication muscular tone on each facial size in Down syndrome patients.

\section{RESULTS}

The outcome of examinations carried out in 25 male and female with Down syndrome were mean and standard deviation ( $\bar{X} \pm \mathrm{SD}$ ) of electromyogram of massetertemporalis muscle synergy i.e. $596.28 \pm 120.34 \mathrm{~mm}^{2} / \mathrm{sec}$, and mean $\pm \mathrm{SD}$ of oral functions total score, i.e. $11.36 \pm$ 3.25. These muscular tone variables were subjected to factor analysis, to attain factor variable of muscular tone.

Table 1. Results of regression test regarding degree of mastication muscular tone effect on facial size in Down syndrome patients

\begin{tabular}{lcc}
\hline $\begin{array}{r}\text { The effect of independent variables on } \\
\text { dependent variables }\end{array}$ & $p$ & $b$ \\
\hline \begin{tabular}{lll} 
Mastication muscular tone factor on & 0.527 & 0.141 \\
facial si ze of lateral growth factor & $(\mathrm{ns})$ & \\
Mastication muscular tone factor on & 0.012 & 0.638 \\
facial si ze of anteroposterior & $(\mathrm{s})$ & \\
growth factor & & \\
Mastication muscular tone factor on & 0.020 & 0.762 \\
facial size of vertical growth factor & $(\mathrm{s})$ & \\
\hline Keterangan: $\mathrm{p}=$ degree of signifgicance; & & \\
$\mathrm{b}$ & $=$ coefficience of regression \\
$\mathrm{s}=$ significant; ns = not significant.
\end{tabular}
\end{tabular}

Results of regression test regarding degree of mastication muscular tone effect on facial size in Down syndrome patients were listed in table 1 . The test showed that the degree of mastication muscular tone has a significant effect on facial size of anteroposterior growth $(\mathrm{p}=$ $0.012)$ and facial size of vertical growth $(p=0.020)$, but not significant on facial size of lateral growth $(\mathrm{p}=0.527)$.

\section{DISCUSSION}

Bone is flexible and may react to functional tension and pressure, thus it can be suggested that form and function are intimately related. Functions that performed by muscles include mastication, deglutition, speech, face expressions, and respiration. Physiologically, tension and pressure can produce alteration in external form and internal structure of the bone. The amount of alteration within bone depends on the tension and pressure encountered. However, pressure from the muscle is within the limits of its morphogenetic 
pattern. The stimulation from muscle to a certain limit (optimal limit) will induce cell growth to become remodeling that may influence bone shape and size. ${ }^{13}$

The mastication process always relates to activities of mastication muscles. The impact of functional stimulation to craniofacial is mainly derived from mastication muscles activity. This stimulation will produce biomechanical forces and Piezo effect to the bone. Both effects will produce the distortion of collagen tissue, and will create both direct and indirect electric potential that induce osteoblastic and osteoclastic process. ${ }^{14}$

Kiliaridis ${ }^{15}$ stated that eating soft diet regularly will reduce the function of mastication, thus fibers of masticatory muscles will be smaller. Consequently, mastication or contraction strength will be reduced and produce changes in bone remodeling. This may influence the craniofacial bone growth. Moreover, Engstrom et al. ${ }^{16}$ demonstrated that rats fed a soft diet will have diminution in degree of mastication function, which will change bone apposition pattern in cortical bone and upper facial sutures. Kiliaridis et al. ${ }^{17}$ proposed that weakened of mastication muscles may influence the size of gonion angle.

In this study, regression test was carried out to observe the effect of degree of mastication muscular tone on facial size in patients with Down syndrome. The result of regression test indicates that the degree of mastication muscular tone has a significant effect on facial size of anteroposterior growth $(\mathrm{p}=0,012)$ and vertical growth $(p=0.20)$, but not significant on facial size of lateral growth $(\mathrm{p}=0,527)$.

Factors of facial size of anteroposterior growth contain the length of maxilla, length of mandibula, and Ar-Go-Me angle (gonion angle). Those parts have a direct correlation to masseter muscle activities when function, considering masseter muscle have insertion on angulus and ramus mandibulae, and its origin is on arcus zygomaticus. ${ }^{18}$

Kiliaridis et al. ${ }^{17}$ also stated that weakened of mastication muscles will reduce mechanical strength, that compress the mandible and resulting changes to gonion angle. The research performed in patients with myotonic dystrophy revealed that weakened of mastication muscle will reduce mechanical compression to the mandible, so the mandible will be pulled downward easily. The downward movement of mandible may be resulted from gravitation or probably by force of suprahyoid muscle downward. The mouth will likely to open, meanwhile posterior teeth will continue to erupt. Thus, anterior open bite will occur. As a result, gonion angle will be larger than normal.

A strong mastication muscle will amplify the rotation of mandible to anterior, thus gonion angle will be narrowed. Diet alteration will cause changes in dimension of maxilla and mandible. Soft diet can diminish the size of mastication muscles. Therefore, functional stimulation to bone will decrease, that may cause rotation of mandible backward, resulting the gonionangle larger than normal. The changes of dimension will directly affect both maxilla and mandible, because origin and insertion of mastication muscles are attached to them. ${ }^{19,20}$

DuBrul $^{21}$ suggested that the site of growth of maxilla complex occurs prominently in several sutures in this region. The suture is running frontward-upward to backward-downward, therefore the maxilla complex grow in up-front direction. This will cause bone apposition in the entire posterior surface of maxilla, thus enlarging maxilla anteroposteriorly. In his study of rats fed a soft diet, Engstrom et al. ${ }^{16}$ demonstrated that soft diet will diminish the degree of mastication function, subsequently bone apposition in upper facial suture will undergo an alteration that affecting the suture closing process. Consequently, facial growth in anteroposterior direction is insufficient.

Based on explanation above, it can be assumed that muscular hypotonia in patients with Down syndrome will decrease the function of mastication, resulted in facial growth insufficiency in anteroposterior direction. Likewise soft diet will decrease muscle strength, muscular hypotonia in patients with Down syndrome most likely to give direct impact to the dimension of maxilla and mandible. In addition, muscular hypotonia will reduce mechanical strength that compress the mandible, thus gonion angle in patients with Down syndrome have a tendency to be larger than normal. For that reason, it can be concluded that the degree of mastication muscular tone in Down syndrome patients has an impact on the maxillary length, mandibular length, and gonion angle, in which all three of them are facial size of anteroposterior growth.

The degree of mastication muscular tone also has a significant impact on facial size of vertical growth $(p=0.020)$. To describe this, masseter and temporalis muscle activities are open and close the mouth when eating, and speaking as well. ${ }^{18}$

Muscular hypotonia, or weakened of masticatory muscles, in Down syndrome patients reduces muscle stimulation to the bone, resulted in insufficiency of facial growth in vertical direction.

DuBrul $^{21}$ proposed that vertical facial growth in subnasal region is augmenting, as a result of resorption in nasal floor and aposition in surface of palatum and alveolar bone, concurrently with teeth eruption. Muscular hypotonia in Down syndrome patients reduces mastication force, so it will also reduce the force from mandibular stroke to alveolar bone in upper jaw and afterward transmitted to palatum. Consequently, remodeling process in subnasal region will not be optimal, that will cause a lack of vertical facial size.

The result revealed that the degree of mastication muscular tone in Down syndrome patients has no influence on facial size of lateral growth $(\mathrm{p}=0.527)$. Considering that fibers of masseter muscle run obliquely and temporalis muscle fibers runs vertically and obliquely, and their main functions are to elevate and retract the mandible, ${ }^{18,21}$ it is most likely that facial size of lateral growth is not influenced by masticatory muscles that largely move vertically in accordance with their fibers direction.

According to DuBrul, ${ }^{21}$ there is only small amount of lateral facial growth in the posterior region because it is limited by os sphenoidale. Or else, it is likely that lateral 
facial growth have already completed in 12 years of age. Therefore, the muscle activity around facial region is not strong enough to exert influence upon lateral facial growth, what is more in Down syndrome patients who have masticatory muscular hypotonia.

The result and discussion above revealed that the degree of mastication muscular tone in Down syndrome patients may influence the facial size of anteroposterior and vertical growth, but not the facial size of lateral growth.

\section{REFERENCES}

1. Sidiarto LD. Aspek neurologik sindroma down dan penanganannya. Jakarta: Simposium Perkembangan Genetika Kedokteran FKUI; 1991.

2. Kumin L. Communication skills in children with down syndrome. A guide for parents. Rockville: Woodbine House Inc; 1994. p. 1-33, 129-41, 193-97.

3. Nanda KS. The developmental basis of occlusion and malocclusion. Chicago: Quintessence Publish Co. Ltd; 1983. p. 29-42.

4. y'Edynak GJ, Iscan MY. Craniofacial evolution and growth. In: Iscan MY, editor. Forensic analysis of the skull. New York: Wiley-Liss, Inc; 1993. p. 11-27.

5. Hoyer H, Limbrock GJ. Orofacial regulation therapy in children with Down syndrome using the methods and appliances of CastilloMoralles. J Dent Child 1990; 442-44.

6. Limbrock GJ, Hoyer H, Scheying H. Regulation therapy by CastilloMoralles in children with Down syndrome: primary and secondary orofacial pathology. J Dent Child 1990; 437-41.

7. Glatz-Noll E, Berg R. Oral dysfunction in children with Down's syndrome: An evaluation of treatment effects by means of videoregistration. Eur J Orthod 1991; 13:446-51.

8. Kaban LB. Pediatric oral and maxillofacial surgery. Philadelphia: WB Saunders Co; 1990.

9. Brandies FH. Cephalometric comparison between children with and without Down's syndrome. Eur J Orthod 1988; 10:255-63.
10. Proffit WR, Fields HW, Ackerman JL, Thomas PM, Tulloch JFC. Contemporary orthodontics. St Louis: The CV Mosby Co; 1986. p. 16-94.

11. Sperber GH, Tobias PV. Craniofacial embryology. $2^{\text {nd }}$ ed. Bristol: John Wright \& Son Ltd; 1976. p 3-5, 57-65, 68-97, 110-120.

12. Suharsini M. Pengaruh hipotonia otot pengunyah terhadap ukuran dan bentuk kraniofasial penderita sindroma down. Disertation. Surabaya: Universitas Airlangga; 1999. p. 63-65.

13. Mokhtar M. Dasar-dasar ortodonti perkembangan dan pertumbuhan kraniodentofasial. Jakarta: Yayasan Penerbitan Ikatan Dokter Indonesia; 1998. p. 3.1-3.26.

14. Enlow DH, Hans MG. Essentials of facial growth. Philadelphia: WB Saunders Co; 1996. p. 18-38, 57-110, 200-11, 265-80.

15. Kiliaridis S. Masticatory muscle function and craniofacial morphology. An experimental study in the growing rat fed a soft diet. Am J Orthod Dentofac Orthop1986; 92:355-56.

16. Engstrom C, Kiliaridis S, Thilander B. The relationship between masticatory function and craniofasial morphology. II A histological study in the growing rat fed a soft diet. Eur J Orthod 1986; 8:271-79.

17. Kiliaridis S, Mejersjo C, Thilander B. Muscle function and craniofacial morphology: a clinical study in patients with myotonic dystrophy. Eur J Orthod 1989; 11:131-38.

18. Heartwell CM, Rahn AO. Syllabus of complete dentures. $4^{\text {th }}$ ed. Philadelphia: Lea \& Febiger; 1986. p. 1-13, 30-40.

19. Varrela J. Effects of attritive diet on cranio facial morphology; a cephalo-metric analysis of a Finnish skull sample. Eur J Orthod 1990; 12:219-23.

20. Mieke S. Pengaruh pola makan pada morfologi rahang, gigi, dan wajah serta akibatnya pada kejadian maloklusi. Disertation. Surabaya: Universitas Airlangga; 1993. p. 98-100.

21. DuBrul EL. Oral anatomy. $7^{\text {th }}$ ed. St Louis: CV Mosby Co; 1980. p. 93-132, 142-73, 200-09. 